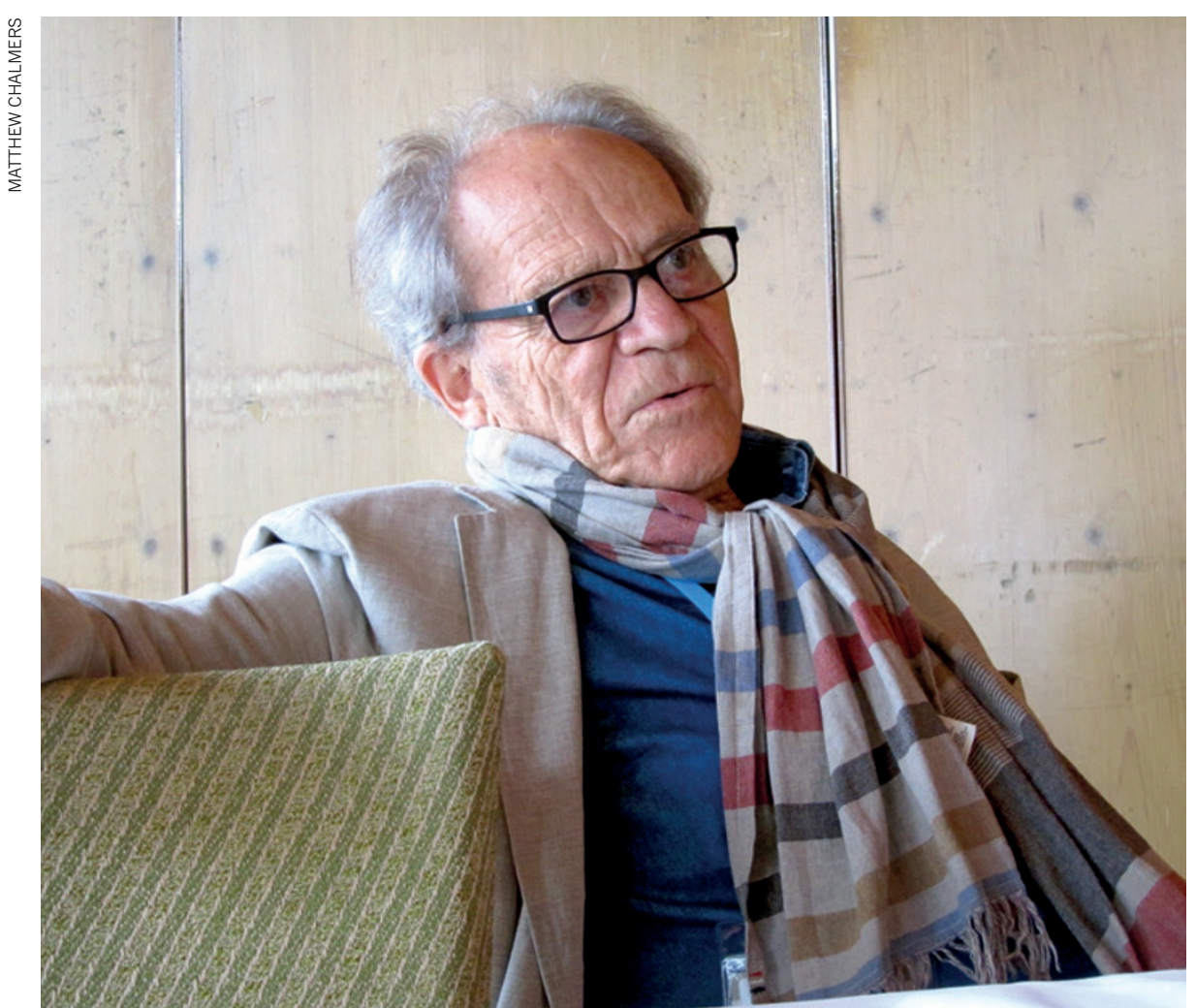

Q\&A Torsten Wiesel

\title{
Progress in sight
}

Torsten Wiesel is president emeritus of Rockefeller University in New York City. He shared half of the 1981 Nobel Prize in Physiology or Medicine with David Hubel for their discoveries concerning information processing in the visual system. He tells Stefano Sandrone about his greatest scientific achievement and his vision of the future.

\section{What kind of student were you?}

I was rather mischievous and not particularly focused on my studies. I was more interested in sport. When I turned 17, I became more serious about academia and began to evaluate myself more. It was then that I decided I would become a doctor. I read a lot and I met lots of different people. I was raised in the largest psychiatric hospital in Sweden, where my father was director and chief psychiatrist. This undoubtedly greatly influenced the development of my values and other aspects of my life.

\section{Why did you choose medicine?}

I went into medicine partly because of my upbringing in the hospital. Also, my eldest brother became schizophrenic in his early twenties and I wanted to better understand his condition. As a doctor I became quickly frustrated with the lack of adequate treatment of mental illnesses, and returned to my professor in neuroscience who allowed me to work in his laboratory for a year. During that year, he received an enquiry from Stephen Kuffler at Johns Hopkins University in Baltimore, Maryland, who was looking for a postdoc. And so it was by pure luck that I ended up working in one of the best labs in the world. This marked the beginning of my scientific career, although it also meant that I never completed my PhD.

What was your relationship like with David Hubel, the other half of your scientific team? When I met David at Johns Hopkins I realized he was a very smart guy and we immediately recognized our shared interests. Though we were very different, we complemented one another. I called him my 'scientific brother' as we were not close friends outside science — our families did not interact and we did not go to the movies or that kind of thing. We usually carried out two experiments per week on Tuesdays and Thursdays, often working through the night, then the next day we would analyse the data and plan the next experiment. It was brilliant how this worked for 20 years.
Were you aware of the importance of your research into the visual system?

We never talked about it. People told me it was important and my response was: the longer the research takes, the better it is. There was a lot of work to be done and although I was aware that people got the Nobel prize for such research and then went on the lecture circuit, I wanted to continue in the lab. I believe that if you decide to do something then you put your whole heart and energy into it. Had my science not worked out, I would have gone back to Sweden to be a doctor. Certainly, in terms of discovery, I got the most satisfaction from our studies of how the visual cortex is able to encode the orientation properties of an object.

\section{How different is the external 'real' world} from what we see?

The external world can be very different to our perception of it, depending on what our senses tell us. Some insects can see in different ways and their world is very different from ours. Because the basic wiring is the same in all humans, we can agree on certain things like colours and textures. But it is also clear that some people are better at certain things than others, such as mathematics, painting or writing. This is related to high-level functioning of the brain. However, we do not even understand the basic circuitry behind auditory perception, such as how we hear music or voices.

Will we ever fully understand the brain? Someone asked me this question after my speech at the Nobel dinner, and I replied: "Never, I hope." Although understanding the brain will be beneficial to helping solve problems associated with ageing, for example, I worry what might happen if governments get access to all the tricks. There are lessons to be learned from the atomic age here. There are things about which we always have to be vigorous and defensive.

\section{What will be the next paradigm shift in neuroscience?}

There are so many problems ranging from cells to circuitries that it is difficult to predict. In my area of competence, neurophysiology, we still need to understand the mechanisms of hearing and the circuitry of higher functions that allow us to recognize objects. I would like to know how the auditory system, with relatively few fibres, analyses information coming into the brain. We have such wonderful abilities to recognize voices as well as faces, yet we have no idea about how the brain and the auditory cortex make this possible. In general, we do not yet know how the brain is wired. In the 1960s and 1970s there was a big effort in artificial intelligence and a lot of resources invested, but it was pretty much a fiasco. The time was not right for that then, but the simultaneous launch of the BRAIN [Brain Research 
through Advancing Innovative Neurotechnologies] Initiative, announced by President Obama in 2013, and the Human Brain Project in Europe, also announced in 2013, might be more timely.

\section{How does Sweden, home to the Nobel prize, treat its laureates?}

The prize is most revered in Asian countries. If you have a Nobel prize and you visit China or Japan you are received as if you were a king. In Sweden less so, because the mentality is that we should all be treated as equals. A friend of mine once requested a table by the window when making a reservation at a restaurant to celebrate my birthday and mentioned that I was a laureate, only to be told that it made no difference. And you don't get better seats in the theatre, either. Here in Lindau it is different, of course. But I would like to see more people giving talks here, even if they are not recipients of the prize, because it shouldn't be an institution for ageing scientists. You want students to be exposed to the best there is.

\section{What tips would you give to a young scientist today?}

Science should be fun: you should enjoy what you do. In this era of 'big science', there are still areas in neuroscience where an individual or small laboratory can make an important contribution, such as the study of the sensory and motor systems and the cortical circuitry underpinning the higher function of recognition of objects and places. My advice for an undecided brilliant young person looking for an area of research is to enter the field with the sincere intention of helping to solve the intriguing questions of how the brain works.

\section{What is the most important lesson you have learnt?}

To respect other people's point of view, even if you disagree. Lots of discoveries in science have been met with claims that they must be wrong, but it is a mistake to say that on the grounds that something doesn't agree with dogma. I have a deep sense of respect for everybody. From a janitor to a president, I deal with each person in the same way.

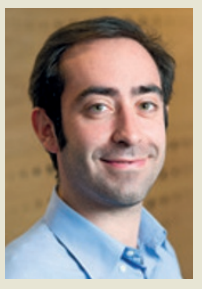

Stefano Sandrone is a PhD student at King's College London. He studies neuroplasticity and connectional neuroanatomy, and has a special

interest in the history of neuroscience.

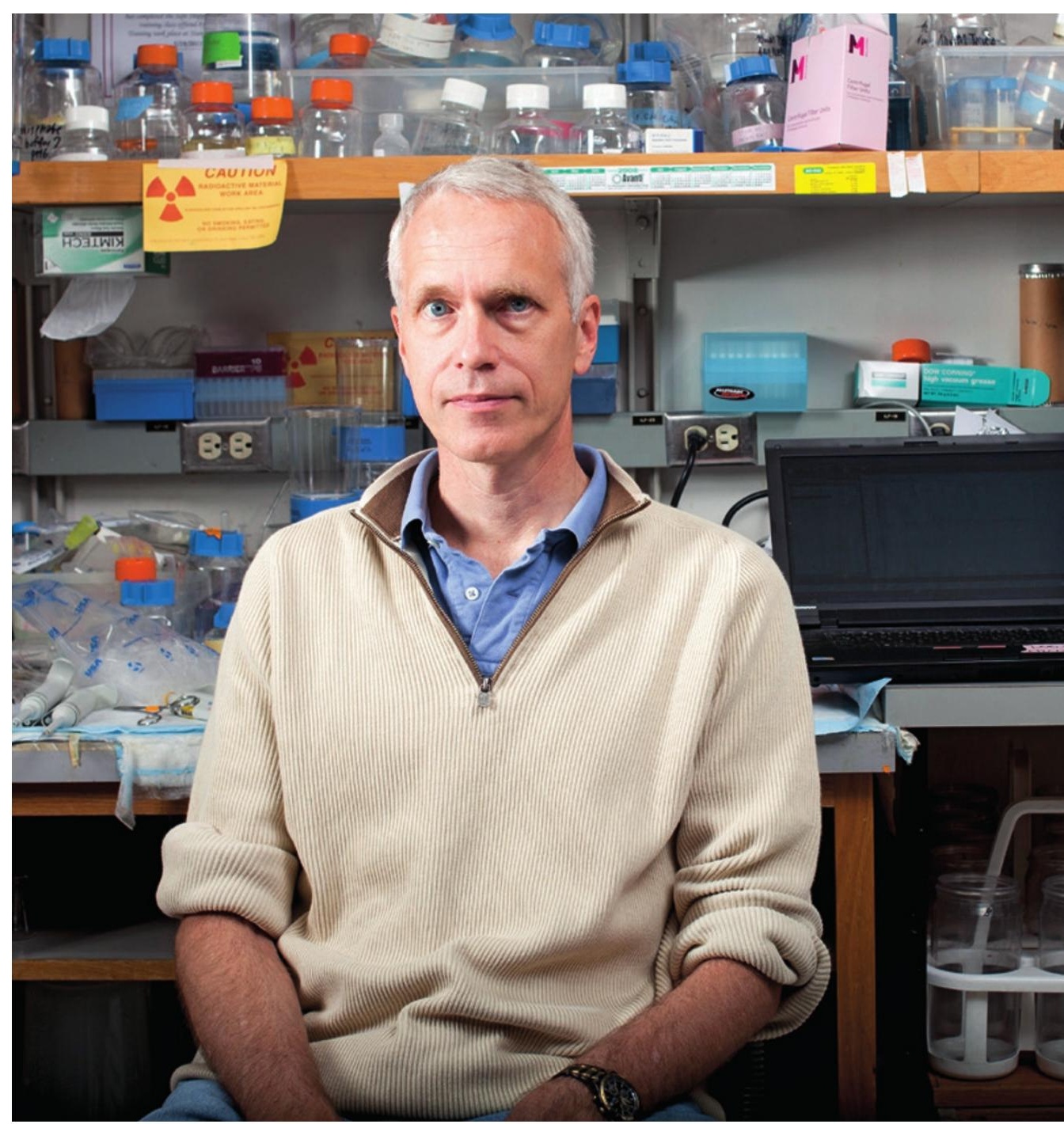

\section{Q\&A Brian Kobilka}

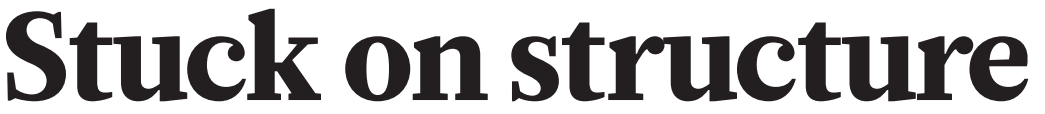

Brian Kobilka shared the 2012 Nobel Prize in Chemistry with Robert Lefkowitz for their studies of $G$ protein-coupled receptors. He is professor of molecular and cellular physiology at the Stanford University School of Medicine in California. Haya Jamal Azouz asks Kobilka what it takes to spend 30 years answering a single research question.

\section{What are G protein-coupled receptors} (GPCRs) and why are they interesting? GPCRs are proteins found on the surface of all cells in the body that recognize and bind hormones and neurotransmitters. Their principal purpose is to transmit a signal to active proteins on the inside of the cell, thereby changing the cell's behaviour. There are more than 800 GPCRs in the human genome. They mediate the majority of the body's response to hormones and neurotransmitters, and are responsible for the senses of sight, smell and taste. GPCRs are involved in so many aspects of normal physiology, including homeostasis. It is interesting to understand how protein structures mediate signalling behaviours; understanding the structures may be helpful in developing more selective and effective drugs for these receptors, which represent approximately $30 \%$ of current drug targets. My initial interest in $\beta$-adrenergic receptors came from

\section{$\rightarrow$ NATURE,COM}

Young scientists meet laureates, in four films: go.nature.com/uzypa2 my clinical experience using $\beta$-agonists to treat asthma and $\beta$-blockers to treat heart disease. 